\title{
Prevalence and Associated Risk Factors of Anaemia in Children aged Six Months to Fifteen-years Admitted to University Teaching Hospital, Lusaka, Zambia
}

\author{
Inambao M. $N^{1}$ and Mulenga $V^{2}$, \\ 1 Paediatric Registrar at University Teaching Hospitals - Lusaka Children's Hospital, Paediatrics and Child Health \\ Master of Medicine (MMed) Trainee at University of Zambia School of Medicine \\ 2 Consultant Paediatrician at University Teaching Hospitals - Lusaka Children's Hospital; MPH, MMed Paediatrics \\ and Child Health \\ Address of Correspondence: Dr Muleya N. Inambao
}

Email: muleyainambao@gmail.com

\begin{abstract}
Background: Anaemia is a public health problem globally affecting 293.1 million children and $28.5 \%$ of these children are in the sub Saharan Africa. The aim of this study was to determine the prevalence of anaemia and the associated risk factors of anaemia in children aged 6 months to 15 years admitted to the University Teaching Hospital. There have been no studies done at University Teaching Hospital to establish the burden of anaemia in children.
\end{abstract}

Methods: A cross sectional study was conducted from July 2016 to December 2016. 351 children were recruited through convenient sampling methods. Data collection sheet was used to collect socio demographic and anthropometry data. The prevalence, associated risk factors of anaemia, and morphological types of anaemia were determined after blood investigations were done. Data analysis was done using SPSS version 21.0. The association between predictors and outcome variables were measured by using by logistic regression and bivariate analysis. Ethical permission was obtained, consent from parents/guardians was taken and confidentiality was maintained.

Results: A total of 351 children were studied. The mean age was 3 years (IOR 2-7 years). 45.9\% were females and $54.1 \%$ were males $(\mathrm{P}=0.12)$. The mean cell volume was 74. 5fL.Malnourised children were $37.9 \%$ among those who were anaemic as compared to $33.7 \%$ in the non-anaemic group. $7.4 \%$ children had positive malaria by rapid diagnostic test (RDT). $23.8 \%$ had a positive sickling test. The prevalence of anaemia was 161/351 (45.9\%). Mild, moderate, severe anaemia was 47/161(29\%), $86 / 161(53 \%)$ and $28 / 161(17 \%)$ respectively. The age group 6 months to 5 years was the most affected with $59 \%$ mildly, $69.8 \%$ moderately and $71.4 \%$ severely anaemic. On bivariate analysis malnutrition, HIV, malaria, age and sex were not associated with anaemia and there was no statistical difference. Logistic regression analysis revealed that presence of haemoglobin $\mathrm{S}$ was the only risk factor independently strongly associated with Anaemia (CI-0.2-0.7), p value-0.001.

Conclusion: Anaemia is a health problem at University Teaching hospital and the under-five age group is the most affected. Predictors of mild, moderate and severe anaemia is sickle cell disease. Therefore, improving on early screening of sickle cell disease and investigating the role of iron deficiency anaemia are some of the strategies to be advocated.

Keywords: Anaemia, Prevalence, Risk factors, Zambia, Africa

\section{INTRODUCTION}

Anaemia is a public health problemaffecting populations in both developed and developing countries with adverse consequences on human health as well as social and economic development 1 . It is estimated globally, that 293.1 million children under five years of age are suffering from anaemia and $28.5 \%$ of these children are from sub-Saharan Africa.1Anaemia is a major public health problem

with a prevalence of $67 \%$, equivalent to 83.5 million children in sub Saharan Africa and the 2008 WHO report estimated prevalence of anaemia in Africa at $64.4 \% .1$.

In Zambia, the prevalence of anaemia among under five children is $65 \%$ according to the 1999 National Survey on Prevalence and Aetiology of Anaemia.2Anaemia is defined as a reduction of red blood cell volume or haemoglobin concentration according to age by $\mathrm{WHO} 3$ as: 
6 months to 6 years $\mathrm{Hb}$ less than $11 \mathrm{~g} / \mathrm{dl}$

6 years to 11 years $\mathrm{Hb}$ less than $11.5 \mathrm{~g} / \mathrm{dl}$

12 years to 14 years $\mathrm{Hb}$ less than $12 \mathrm{~g} / \mathrm{dl}$

According to the WHO report (2011), anaemia is defined as haemoglobin level below 12 grams per decilitre in children aged 12 to 14 years and in children aged 6 to 11 years as below 11.5grams per decilitre 3: Severe anaemia is defined as Haemoglobin level below $7 \mathrm{~g} / \mathrm{dl}$ in children aged 6 to14 years of age. Moderate anaemia is defined as Haemoglobin level $7 \mathrm{~g} / \mathrm{dl}$ to $9.9 \mathrm{~g} / \mathrm{dl}$ in children aged 6 to 14 years of age. Mild anaemia is defined as Haemoglobin level $10 \mathrm{~g} / \mathrm{dl}$ to $11.4 \mathrm{~g} / \mathrm{dl}$ in children aged 6 to 11 years.

Anaemia can also be classified according to changes associated in the red cell size and shape 4. Morphological classification of anaemia is based on mean corpuscular volume and haemoglobin concentration. 4

Anaemia is a critical health concern because it affects growth and energy levels adversely.5 It damages immune mechanisms and is also associated with increased morbidity.6,7 It occurs at all age groups but is more prevalent in children. Young children from low income families have a higher risk for developing anaemia due to iron deficiency that occurs as a result of high demand for iron during the period of rapid growth. 8

Anaemia aetiology has a multifactorial nature which is mainly due to deficiency in micronutrients and parasitic infections with malaria being the most common parasitic infection associated with anemia.9,10,11 Iron deficiency is the main micronutrient that contributes to anemia.12 The other risk factors for anaemia include intestinal worm infestations, HIV infection, haematological malignancies and sickle cell disease. 13

Anaemia is an important cause of mortality in African children admitted to hospitals, but is rarely cited as a cause of death outside hospitals. 14 Severe Anaemia which is defined as haemoglobin concentration less than 5 gram per decilitre is a major cause of sickness and death among children in sub-Saharan Africa according to a study done in Malawi.15

In various settings, $12 \%$ to $29 \%$ of hospitalized children are severely anaemic and the in-hospital case fatality rate in these children is $8 \%$ to $17 \% .16$ Studies in African countries have showed that for children less than five years of age, the percentage of deaths due to anaemia is similar to reports from highly endemic malaria areas, as Sierra Leone (11.2\%), Congo (12.2\%) and Kenya (14.3\%).17 The highest risks of deaths occurred with non-transfused paediatric emergency admissions at about $58.1 \%$ in a prospective followup study of a cohort of children.18, 19.

A study done in Zambia in 2014 by Daly found that children aged 12 months and above who were receiving minimal dietary iron were associated with reduced risk of being moderately or mildly anaemic. 20.

UTH Paediatric reports for 2012 to 2014 indicate that severe anaemia is one of the causes of admissions and mortality in paediatric wards. The true burden of mild and moderate anaemia remains unknown. Mild and moderate anaemia is associated with long term deliberating side effects. Full blood counts are routinely done, but notably anaemia cases are treated as such only when very low haemoglobin of less 5 grams per decilitre are noted, according to UTH protocol and follow up is based on the clinical response. Findings of the study will provide data on magnitude of problem of anaemia and improve on clinical care by early identification and treatment of anaemia.

The aim of the study was to establish the extent of the problem of mild, moderate, severe anaemia in children aged six months to fifteen years and document the common associated risk factors as well as red cell indices of anaemia.Specific objectives were to determine: proportion of children with anaemia aged 6 months to 15 years defined by WHO as Haemoglobin less than $11 \mathrm{~g} / \mathrm{dl}$; the proportion of children with mild, moderate and severe Anaemia among children aged 6 months to 15 years; risk factors associated with Anaemia among children aged 6 months to 15 years; and to describe the different morphological types of anaemia in children aged 6 months to 15 years admitted to UTH.

\section{METHODOLOGY}

The study was a cross sectional study with focus on children aged 6 months to 15 years admitted to UTH Lusaka Children's Hospital from the outpatient department (A01) and Admission ward, between July 2016 and December 2016. Sample size calculated by the prevalence formula was 350 . Atotal of 351 eligible children were enrolled in the 
study. Informed consent was obtained from parents /guardians of children aged 6 months to 15 years who were eligible for the study.

The study questionnaire was administered, and anthropometry measurements were taken. The anthropometry included height measured using the stadiometer and weights using the weight scales. Collection of a blood sample of maximum of $2 \mathrm{mls}$ of blood sample was done from a peripheral vein into a labelled EDTA bottle to run the following tests full blood count, sickling test, peripheral smear and taken to the UTH Haematology laboratory. A skin prick for MPS/RDT was done to check for presence of malaria parasites. Stool was not done owing to the short duration of hospitalization of some patients.

HIV rapid test was done by the HIV counsellors via routine provider-initiated HIV testing and counselling (PITC). Nutritional status was assessed using the SD score: weight for height/length and was classified accordingly.Full blood count parameters included white blood cell count, red cell count, haemoglobin, haematocrit, mean cell volume (MCV), mean corpuscular haemoglobin concentration (MCHC), red cell distribution width (RDW), reticulocyte count and platelet. Peripheral blood smear was done to describe the morphology and distribution of red blood cells, white blood cells and platelets. Malaria parasite slide/Rapid diagnostic test (MPS/RDT), HIV status and nutritional status were the risk factors assessed for anaemia.

Approval to conduct the study was obtained from research ethics committee ERES. Permission to conduct the study was sought from the department of paediatrics and child health and UTH administrative management. Written consent was obtained by signature or thumb print after explanation of the study and procedure in simple English and local languages was done to parents/ guardians. Assent forms were signed by children aged 7 years and above and were able to read and write.

\section{RESULTS}

\section{Baseline Characteristics}

A total of 351 children aged between 6 months to 15 years were recruited between the period July 2016 to December 2016. There were more males $(52.2 \%)$ than females affected in the anaemic group. The median age was 3.0 years. Majority of the patients $(93.2 \%)$ did not have any chronic illness. $35.6 \%$ of the total population had some level of malnutrition.

The most affected age group was 6 months to 6 years at $67.1 \%$ in the anaemic group. Bivariate analysis revealed that the children below 6 years were significantly more likely to have severe anaemia than their counter part. More details of the patient's characteristic are described in Table 1. The prevalence of anaemia in the study children was 161/351(45.9\%). Among those with anaemia $67.7 \%$ were between the age group 6 months to 6 years. Among the age group 6 years to 12 years, $25.5 \%$ had anaemia and $7.5 \%$ among the age group 12 to 15 years had anaemia as shown in Table 1. 
Table 1. Summary of Descriptive Statistics $(\mathbf{n}=\mathbf{3 5 1})$

\begin{tabular}{|c|c|c|c|c|c|c|c|}
\hline Variable & Frequency & percentage & $\mathbf{N}$ & $\%$ & $\mathbf{N}$ & $\%$ & \\
\hline \multicolumn{8}{|l|}{ Sex } \\
\hline Female & 161 & 45.9 & 84 & $44.2 \%$ & 77 & $47.8 \%$ & 0.5 \\
\hline Male & 190 & 54.1 & 106 & $55.8 \%$ & 84 & $52.2 \%$ & \\
\hline \multicolumn{8}{|l|}{ History of chronic illness } \\
\hline No & 327 & 93.2 & 179 & $94.2 \%$ & 148 & $91.9 \%$ & 0.4 \\
\hline Yes & 24 & 6.8 & 11 & $5.8 \%$ & 13 & $8.1 \%$ & \\
\hline \multicolumn{8}{|l|}{ Nutrition status } \\
\hline Not Malnourished & 227 & 64.4 & 126 & $66.3 \%$ & 100 & $62.1 \%$ & 0.41 \\
\hline Malnourished & 125 & 35.6 & 64 & $33.7 \%$ & 61 & $37.9 \%$ & \\
\hline \multicolumn{8}{|l|}{ Age group } \\
\hline $0.5-5.9$ Years & 235 & 67 & 127 & $66.8 \%$ & 108 & $67.1 \%$ & 0.86 \\
\hline $6-11.9$ Years & 87 & 24.8 & 46 & $24.2 \%$ & 41 & $25.5 \%$ & \\
\hline $12-15$ Years & 29 & 8.3 & 17 & $8.9 \%$ & 12 & $7.5 \%$ & \\
\hline \multicolumn{8}{|l|}{ Malaria parasite slide } \\
\hline Negative & 325 & 92.6 & 174 & $91.6 \%$ & 151 & $93.8 \%$ & 0.43 \\
\hline Positive & 26 & 7.4 & 16 & $8.4 \%$ & 10 & $6.2 \%$ & \\
\hline \multicolumn{8}{|l|}{ Sickling test } \\
\hline Negative & 267 & 76.1 & 158 & $83.2 \%$ & 109 & $67.7 \%$ & $<0.01$ \\
\hline Positive & 84 & 23.9 & 32 & $16.8 \%$ & 52 & $32.3 \%$ & \\
\hline \multicolumn{8}{|l|}{ RBC Morphology } \\
\hline Abnormal & 267 & 76.1 & 177 & $93.2 \%$ & 90 & $55.9 \%$ & $<0.01$ \\
\hline Normal & 84 & 23.9 & 13 & $6.8 \%$ & 71 & $44.1 \%$ & \\
\hline \multicolumn{8}{|l|}{ Morphological appearance } \\
\hline Normocytic Normochromic & 202 & 57.6 & 131 & $68.9 \%$ & 71 & $44.1 \%$ & $<0.01$ \\
\hline Microcytic Hypochromic & 125 & 35.6 & 50 & $26.3 \%$ & 75 & $46.6 \%$ & \\
\hline Macrocytic Normochromic & 24 & 6.8 & 9 & $4.7 \%$ & 15 & $9.3 \%$ & \\
\hline \multicolumn{8}{|l|}{ White blood cell morphology } \\
\hline Abnormal & 12 & 3.4 & 2 & $0.1 \%$ & 10 & $6.2 \%$ & $\mathrm{P}=0.01$ \\
\hline Normal & 339 & 96.6 & 188 & $98.9 \%$ & 151 & $93.8 \%$ & \\
\hline \multicolumn{8}{|l|}{ Platelet morphology } \\
\hline Abnormal & 14 & 4.0 & 1 & $0.5 \%$ & 13 & $8.1 \%$ & $\mathrm{P}<0.01$ \\
\hline Normal & 337 & 96.0 & 186 & $99.5 \%$ & 148 & $91.9 \%$ & \\
\hline \multicolumn{8}{|l|}{ Child HIV serostatus } \\
\hline Negative & 320 & 91.2 & 176 & $92.6 \%$ & 144 & $89.4 \%$ & 0.29 \\
\hline Positive & 31 & 8.8 & 14 & $7.4 \%$ & 17 & $10.6 \%$ & \\
\hline
\end{tabular}




\section{Proportion of mild, moderate, severe Anaemia}

The grading of anaemia was assessed by using the WHO cut off values. Regarding severity, among the anaemic children 47/161 (29\%) had mild anaemia, 86/161 (53\%) had moderate anemia, and 28/161 (17\%) had severe anaemia (Figure 1). The prevalence of anaemia as shown in Table 1 decreased consistently with increase in age reaching $7.5 \%$ in later years (12 to 15 years).children less than 6 years had a higher prevalence $(67.7 \%)$. The high prevalence in this age group could be explained due to increased demand due to rapid growth, poor complementary feeding practices at the time of weaning around six months of age and increased activity due to achieved milestones.

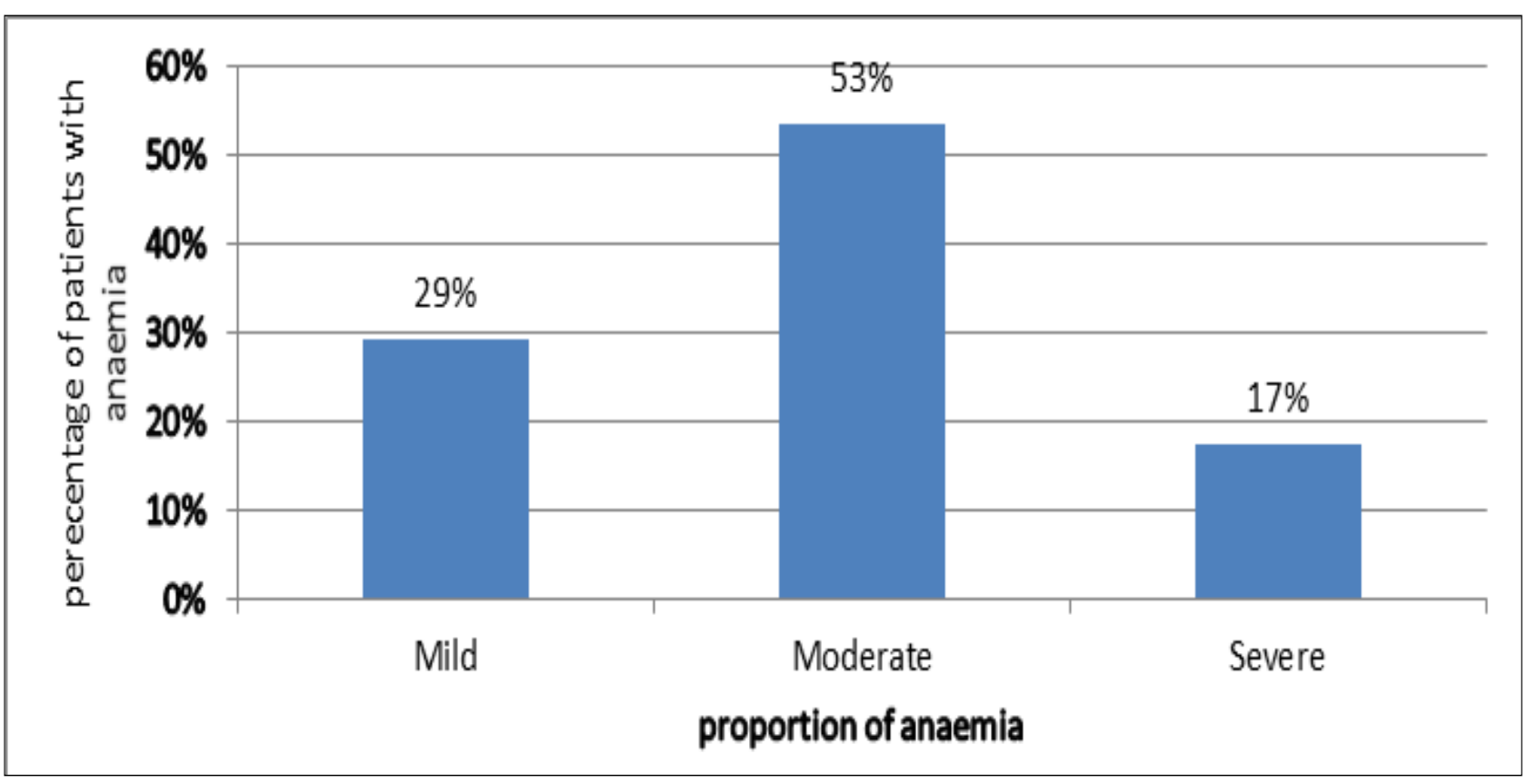

Figure 1: Anaemia levels in the anaemic children $(n=161)$

Table 2 shows a cross-tabulation of age group versus anemia levels. A greater proportion of children with severe anemia was observed in the lower age group 6 months to 5.9 years. The prevalence of mild, moderate and severe Anaemia in this age group was $25.9 \%, 55.6 \% \%$ and $18.5 \%$ respectively.

\section{Morphological types of Anaemia}

Three morphological types of Anaemia were observed: normocytic normochromic, microcytic hypochromic and macrocytic anaemia as shown in Figure 2. Majority had microcytic hypochromic $46.6 \%$ followed by normocytic normochromic $44.1 \%$ and macrocytic normochromic were $9.3 \%$, $\mathrm{P}$ value $<0.01$.

Table 2: Level of anaemia in the age groups

\begin{tabular}{|c|c|c|c|c|c|}
\hline \multirow{9}{*}{ Age Group } & & \multicolumn{4}{|c|}{ Anaemia Level } \\
\hline & & Mild $n(\%)$ & Moderate $n(\%)$ & Severe $n(\%)$ & Total (\%) \\
\hline & \multirow{2}{*}{0.5 - 5.9 Years } & $(28 / 108)$ & $(60 / 108)$ & $(20 / 108)$ & $108(67)$ \\
\hline & & $25.9 \%$ & $55.6 \%$ & $18.5 \%$ & \\
\hline & \multirow{2}{*}{$6-11.9$ Years } & $(15 / 41)$ & $(20 / 41)$ & $(6 / 41)$ & $41(25)$ \\
\hline & & $36.6 \%$ & $48.8 \%$ & $21.4 \%$ & \\
\hline & \multirow{2}{*}{12 - 15 Years } & $(4 / 12)$ & $(6 / 12)$ & $(2 / 12)$ & $12(7.5)$ \\
\hline & & $33.3 \%$ & $50.0 \%$ & $16.7 \%$ & \\
\hline & & & & & $161(100)$ \\
\hline
\end{tabular}




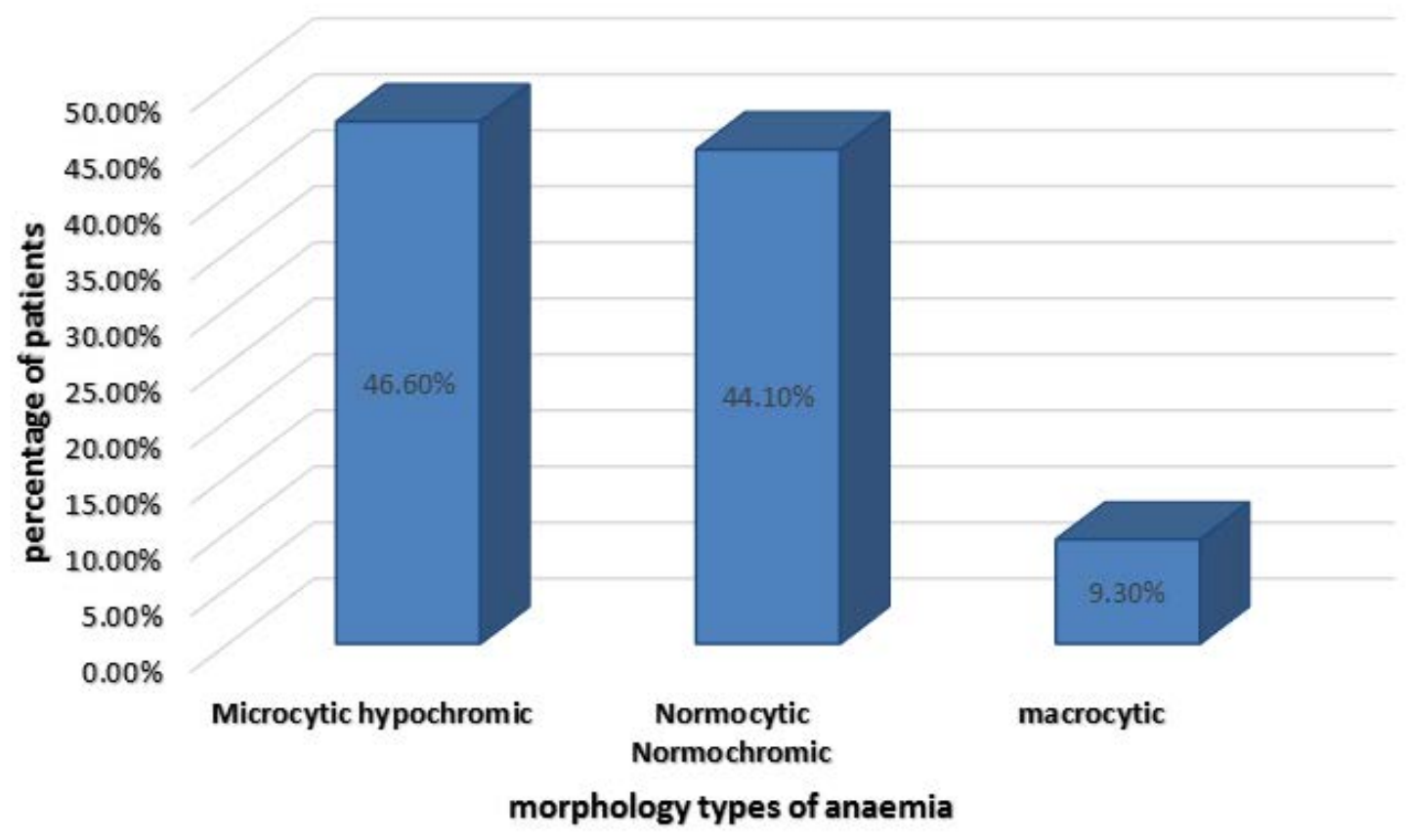

Figure 2. Morphological types of anaemia

\section{Risk factors of anaemia}

There were $7.4 \%$ (26/351) children in the overall population studied with positive RDT malaria, Table 1. Among the anaemic group $6.2 \%(10 / 161)$ had positive RTmalaria.There were $23.9 \%$ (84/351) children with positive sickling test results unknown before the study (Table 1). Of those found with Anaemia, 32.3\% (52/161) tested positive for presence of haemoglobin S. (Table 3) and 8.8\% (31/351) children tested positive for HIV in the overall population, while in the anaemic group, $10.6 \%$ (17/161) tested positive for HIV (Table 3).

\section{Table 3: Risk factors of anaemia}

\begin{tabular}{|l|c|r|}
\hline $\begin{array}{l}\text { Clinical } \\
\text { characteristics }\end{array}$ & Category & \multicolumn{1}{|c|}{$\begin{array}{c}\text { Anaemia N } \\
(\%)\end{array}$} \\
\hline \multirow{2}{*}{ Malaria } & Positive & $10(6.2)$ \\
\cline { 2 - 3 } & Negative & $151(93.8)$ \\
\hline \multirow{2}{*}{ Malnutrition } & Positive & $61(37.9)$ \\
\cline { 2 - 3 } & Negative & $100(62.1)$ \\
\hline \multirow{2}{*}{$\begin{array}{l}\text { Sickle cell } \\
\text { disease }\end{array}$} & Positive & $52(32.3)$ \\
\cline { 2 - 3 } HIV & Negative & $109(67.7)$ \\
\cline { 2 - 3 } & Positive & $17(10.6)$ \\
\cline { 2 - 3 } & Negative & $144(89.4)$ \\
\hline
\end{tabular}

A significant proportion of the children were not malnourished 226/351 (64.4\%) and 125/351 (35.6\%) were malnourished as shown in Table 1.
The level of malnutrition for the malnourished children was as follows; $11.2 \%(14 / 125)$ being severely malnourished, weight for height score $<-3$; $20 \%(25 / 125)$ had moderate malnutrition with weight for height score between -3 and -2 SD and $68.8 \%(86 / 125)$ had weight for height score between median and -1SD.

\section{Haemoglobin, red cell indices, peripheral blood smear.}

In the overall population studied the mean haemoglobin was $11.03 \mathrm{~g} / \mathrm{dl}$ and the mean PCV packed cell volume was $32.1 \% \pm 0.79$ while the mean MCV cell volume was $74.5 \mathrm{fl} \pm 10.64$ and mean $\mathrm{MCH}$ cell haemoglobin was $24.8 \mathrm{pg} \pm$ 4.94. There were $267 / 351$ (76.1\%) children with abnormal RBC morphology and 84/351 (23.9\%) had normal RBC morphology among the total population studied. Of these, $57.5 \%$ (202/351) children had normocytic RBC, 35.6\% (125/351) microcytic RBC, and 6.8\% (24/351) macrocytic RBC (Table 1). In the study population, 3.4\% (12/351) children had abnormal WBC including neutrophilia, leucocytosis and 4\% (14/351) had abnormal platelet morphology-thrombocytosis (Table 1), possibly due to infection. Among the anaemic group 55.9\% (90/161) had abnormal RBC morphology including anisocytosis, target cells both of which signify anaemia, whist and $44.1 \%$ (71/161) had normal RBC morphology. 


\section{Bivariate analysis of study variables}

The PCV, MCV, MCH, reticulocyte count were high predictors of anaemia $p$ value $<0.01$.
Table 4 shows bivariate tests for association with anaemia. Positive Sickling test results were significantly associated with anaemia (P-value $<0.01)$.

\section{Table 4. Bivariate analysis for continuous study variables}

\begin{tabular}{|c|c|c|c|}
\hline Variable & $\begin{array}{c}\text { Not } \\
\text { Anemic }\end{array}$ & Anemic & P-value \\
\hline \multicolumn{4}{|l|}{ Age } \\
\hline (median, SD) & $3.0,5.0$ & $3.0,6.0$ & 0.4 \\
\hline \multicolumn{4}{|l|}{ Body weight (kg) } \\
\hline (median, SD) & $13.4,10.3$ & $13.0,11.0$ & 0.53 \\
\hline \multicolumn{4}{|l|}{ Height (cm) } \\
\hline (mean, SD) & $99.21,21.49$ & $97.63,23.09$ & 0.51 \\
\hline \multicolumn{4}{|l|}{ PCV packed cells } \\
\hline (mean, SD) & $36.37,5.69$ & $25.93,6.82$ & $<0.01$ \\
\hline \multicolumn{4}{|l|}{ MCV cell volume } \\
\hline (mean, SD) & $76.43,8.36$ & $72.25,12.48$ & $<0.01$ \\
\hline \multicolumn{4}{|l|}{$\mathrm{MCH}$ cell haemoglobin } \\
\hline (mean, SD) & $25.56,3.06$ & $23.85,6.38$ & $<0.01$ \\
\hline \multicolumn{4}{|l|}{ Reticulocyte count } \\
\hline (median, SD) & $0.91,0.57$ & $1.38,3.08$ & $<0.01$ \\
\hline \multicolumn{4}{|c|}{ Absolute reticulocyte count } \\
\hline (median, SD) & $0.04,0.03$ & $0.05,0.11$ & $<0.01$ \\
\hline
\end{tabular}

\section{Logistic Regression Analysis Predicting Anemia}

To control the effect and predict the most important determinant of anaemia, logistic regression was performed as shown in Table 5. This showed that presence of haemoglobin-S was the only clinical characteristic found to be independently associated with anaemia. Malnutrition, HIV, malaria, age sex were all not associated with anaemia in the study.

\section{Table 5. Logistic regression predicting anaemia}

\begin{tabular}{|l|l|l|l|l|l|l|l|l|l|}
\hline & & B & S.E. & Wald & Df & Sig. & Exp(B) & 95\% & $\begin{array}{l}\text { C.I.for } \\
\text { EXP(B) }\end{array}$ \\
\hline \multirow{3}{*}{ Step $1^{\text {a }}$} & & & & & & & & Lower & Upper \\
\cline { 2 - 10 } & sickling (1) & -.857 & .257 & 11.124 & 1 & .001 & .425 & .257 & .702 \\
\cline { 2 - 10 } & Constant & .486 & .225 & 4.669 & 1 & .031 & 1.625 & & \\
\hline
\end{tabular}

a. Variable(s) entered on step 1: sickling.

\section{DISCUSSION}

In this study 351 patients were studied and the finding of the magnitude of anaemia at $45.9 \%$ is considered as a severe public health problem according to WHO standards. This reflects the magnitude of the disease among hospitalized children at UTH children's hospital. The prevalence of anaemia in the study is in agreement with those related studies done in developing countries like in studies done in Tanzania, where the prevalence of anaemia was between $44-76 \%$ and in Nigeria where researchers found a prevalence of moderate to severe anaemia at $49.2 \%$ with the most affected group being the age group between $6-12$ months.23,46Studies in Uganda found prevalence of anaemia in children aged 6 to 59 months at $58.8 \% .48$

Present finding of the high prevalence of anaemia in the study at $45.9 \%$ is a reflection that the burden of anaemia in children admitted to UTH is critical and it reflects the need for 
programmatic implications like routine screening for anaemia, nutritional support and also possible poor socioeconomic living conditions that need to be addressed.

The prevalence of mild, moderate and severe anaemia in the study population was $29 \%$, $53 \%, 17 \%$ respectively, similar to the findings in West Africa. Researchers in West African countries-Burkina Faso, Mali and Ghana found the prevalence of mild, moderate and severe anaemia at $24.3 \%, 64.3 \%$ and $10.6 \%$. However, these findings were different from the studies in Tanzania where mild, moderate and severe anaemia were $87 \%, 19 \%$ and $3 \%$ respectively. The study found a higher prevalence of severe anaemia at $17 \%$ as compared to other researchers and this could be multifactorial including the fact that UTH children's hospital receives a huge number of referred patients and UTH being the highest referral hospital where blood transfusion is easily accessible. The implication of this observation is that there is need for anaemia control programmes like dietary supplementation, control of malaria and routine deforming.

Anaemia continues to be a significant health problem in the developing world.1The criterion for determining the presence of anaemia recommended by WHO are based on the haemoglobin cutoff values for age and sex with an additional epidemiological criterion for assessing the severity and magnitude of the problem.

There was no statistically significant difference between gender $(\mathrm{p}=0.5)$ and anaemia affecting $54.1 \%$ of boys and $45.9 \%$. Researchers in Tanzania found a similar trend with females at $42.7 \%$ and males at $53.3 \% 38$ and their conclusion was that male childrenwere likely to be at risk of being anaemic.39However, researchers in Nigeria found that there was no association of anaemia and gender.46

The prevalence of anaemia in the study was found to vary between age groups with the most affected being age group below 6 years at prevalence of $67.1 \%$, the age group 6-11 years at $25.5 \%$ and $12-15$ years at $7.5 \%$. It was observed that the risk of having anaemia decreased with advance in age This was as the case found in studies in Kenya where the younger age of the child was found to be significantly associated with anaemia.25The younger the age, the more susceptibility to anaemia compared to a 14 -year- old counter part25Studies in West Africa in Burkina Faso, Mali, and Ghana found similar trends of anaemia prevalence by age. 42

The findings indicate that this is the first study showing the magnitude of anaemia in children below 6 years admitted to UTH, children's hospital. The possible explanation is that this age group is a period of increased body demand due to rapid physical development, increased activity due to achieved motor milestones and also early weaning poses nutritional deficiencies due to poor complementary feeding practices and therefore nutritional intervention in this age group becomes critical. This represents a powerful tool of advocacy to influence national policies and programmes and invest in child nutrition.

The morphological types of anaemia in the study were as follows; $44.1 \%$ had normocytic, normochromic anaemia, $46.6 \%$ had microcytic hypochromic Anaemia and 9.3\% had macrocytic hypochromic anaemia. A study done in under five children in Tanzania observed that the majority of these children had microcytic hypochromic anaemia at $37.5 \%, 33.3 \%$ had normocytic normochromic anaemia and $0.33 \%$ had macrocytic normochromic anaemia.47Those with microcytic hypochromic anaemia had low ferritin levels.

The findings in the study of higher percentage with microcytic hypochromic anaemia may be related to nutrition at different levels but further evaluation /studies are proposed to establish the exact causes of the study findings.

In terms of the red blood cell indices of the study population, the mean packed cell volume was $25.93 \%,(6.82 \mathrm{SD})$ in those with anemia. Similar results were found in Sudan where the mean packed cell volume was $36.59 \mathrm{fl}$, (3.51SD).45The mean cell volume was $72.25 \mathrm{fl}$, (SD 12.48) in the study population was skewed towards iron deficiency anaemia of whatever cause. Similar studies found an MCV of 77.83fL (SD 8.11)45The mean cell haemoglobin was $23.85 \mathrm{pg}$, (SD 6.38). This was in keeping with what researchers in Sudan found, where $\mathrm{MCH}$ was 25.88pg, (SD $3.55) .42$ The reticulocyte median was 1.38 ,(IQR $3.8, \mathrm{P}<0.01)$. Studies in west Africa found the mean value of reticulocyte at 1.55 and have attributed higher reticulocyte counts to be associated with malaria and hemolytic Anaemia such as sickle cell disease.43It can be concluded that the red cell morphology and red blood cell indices are to be 
incorporated in establishing the possible aetiology of these anaemias in children.

The study found $6.2 \%$ with malaria positive slide/ by RDT among those who were anaemic as compared to $8.4 \%$ in those who were not anaemic. In this study malaria by rapid test was not strongly associated with anaemia but could possibly have been significantly associated with severe anaemia. This is not in keeping with studies that have shown that malaria is associated with anaemia, especially among those with severe Anaemia, according to researcher in Uganda where prevalence of anaemia and malaria was $27.7 \% .46$ The reduction in malaria findings in the study is due overall to the reduction in malaria burden.

The study found that presence of the haemoglobin $\mathrm{S}$ was associated with anaemia. There were $32.3 \%$ children with positive sickling test among those who were found to be anaemic. Logistic regression revealed that the presence of the haemoglobin $\mathrm{S}$ was highly associated with anaemia. This was in keeping with studies done in Nigeria where sickle cell trait was seen in $14.3 \%$ of anaemic children.41One recommendation from these findings in the study is to have a national strategy on the issue of sickle cell disease by either including newborn or early school enrolment screening.

The study found that $37.9 \%$ of anaemic children were also malnourished. Of those $11.2 \%$ were severely malnourished, $20 \%$ moderately malnourished and $68.8 \%$ had mild malnutrition according to WHO definition. The difference was not statistically significant. This finding was in keeping with studies in Uganda which showed that there was no direct association between anaemia and child nutritional status.46The findings are a reflection that severe acute malnutrition is still a problem in children and there is need to continue addressing the problem at a national programme making policy level.

The study found that $8.15 \%$ of those with anaemiahadabnormal platelets on peripheral smear, $\mathrm{p}<0.01$. Abnormalities included thrombocytosis and thrombocytopenia. These results suggest that abnormal platelets could have been due to infection or micronutrient deficiencies like iron deficiency. Studies done in Ethiopian children show that thrombocytosis is usually accompanied by iron deficiency anaemia.41 About $6.2 \%$ of those with anemia were found with abnormal white blood cells $\mathrm{p}=0.01$ including neutrophilia, lymphocytosis, which highly suggest co-infection with either bacterial or viral and anaemia. The other explanation is that the leucocytosis in children with sickle cell disease could have been a result of immature Red blood cells that are counted as lymphocytes on the machine. Further evaluation of these children is required.

The study found that $10.6 \%(\mathrm{p}=0.29)$ of those who were anaemic were HIV positive. There was no association found with anaemia although, Studies in South Africa found that anaemia was directly associated with HIV infection in children.49This is because anaemia is a common manifestation of paediatric HIV infection and nutritional anaemia in HIV infected children.49The possible explanation of the non-association in this study is that the the sample size was the result of HIV seropositivity and not based on the young children's definitive HIV status.

\section{CONCLUSION}

Anaemia is a health problem at UTH children's hospital and the under-five age group is the most affected. The prevalence of anaemia in children aged 6 months to 15 years admitted to UTH was found to be $45.9 \%$. Proportion of mild Anaemia was $29 \%$. moderate anaemia $53 \%$ and severe anaemia $17 \%$. The common red blood cell morphological type of anaemia was microcytic hypochromic anaemia at $46.6 \%$. The presence of hemoglobin-S was directly associated with anaemia in the study. Therefore, improving on early screening of sickle cell anemia, nutritional support intervention, routine screening of anaemia of any cause, regular deworming of children under five years of age are some of the strategies to be advocated.

The following were the recommendations; Anaemia is common among children referred to a tertiary Hospital and should deliberately be looked for and treated promptly, Preventative strategies including early screening of sickle cell disease, screening of anaemia and deworming must target all under-fives regardless of their clinical status or haemoglobin levels, there is need for community awareness and intensified screening at primary health care level so that children with anaemia are identified early and treated or referred to higher level hospitals and further studies are needed to establish the magnitude of the various aetiologies of anaemia in paediatric patients at UTH including iron deficiency anaemia. 
The study limitations were that Some of the children who were eligible for recruitment were missed due to inability to cover the admission site/ $\mathrm{AO} 1$ at all times during the recruitment period, this is a Hospital based study and a select population, hence no reflection on the community as only very ill patients are referred to the tertiary hospital and challenges to collect to stool as some patients had a very short duration of hospital stay.

\section{ACKNOWLEDGEMENTS}

I would like to express my sincere gratitude to the late Prof Chintu for the support rendered throughout this process.

I wish to thank Dr Chabala for the guidance.

I am grateful to Mr E phiri and Mr Chris for the help rendered in ensuring that enrolment and collection of all results was done.

Many thanks to Mr W Mbuzi, haematology laboratory for working on the samples.

\section{REFERENCES}

1. Benoist B, McLean E, Egll I, Cogswell M (2008) Worldwide prevalence of Anaemia 19932005: WHO.

2. World Health Organization (2009). Global database on Anaemia: Public Health Nutrition, 12:444-454.

3. Chatterjee A, Bosch RJ, Kupka R, Hunter DJ, Msamanga GI, Fawzi WW (2010) predictors and consequences of Anaemia among antiretroviral-naïve HIV-infected and HI uninfected children in Tanzania. Public health nutrition, 13:289-296.

4. WHO (2011): Haemoglobin Concentration for the diagnosis of Anaemia and assessment of severity: 1-6.

5. CDC (1989) Criteria for Anaemia in children and childbearing aged women, Morbidity and mortality weekly report,38(22):400-404

6. World Health Organization Report (2002). Reducing risks, promoting healthy life: 449-93

7. Obonyo C, Steyerber E, Oloo A, Habbema J. (1998). Blood transfusion for severe malaria related Anaemia in Africa: A decision analysis. Am J Trop med Hyg:525-530.

8. Lawless J, Latham M, Stephenson L, Kinoti S. (1994). Iron supplementation improves appetite and growth in anaemic Kenyan primary school children. The J Nutrition 124: 654.
9. Brian BJ, Premji Z, Verhoeff F (2001). Iron deficiency Anaemia: Reexamining the nature and magnitude of the public Health Problem. An analysis of Anaemia and child mortality. World health, 131:636-648.

10. Brooker S, Akhwale W, Pullen R, Estambale B, Clarke SE, Snow RW, Hotez PJ. (2007). Epidemiology of plasmodium-helminth co infection in Africa: populations at risk, potential impact on Anaemia and prospects for combining control. Am J Trop MedHyg 77:88-98.

11. Ekvall H. (2003). Malaria and Anaemia.Curr Opin Haematol 10:108-114.

12. Ong'echa J, Keller C, Were T, Ouma C, Otieno R, et al. (2006) Parasitemia, anemia, and malarial anemia in infants and young children in a rural holoendemic plasmodium falciparum transmission area. Am J Trop Med Hyg 74: 376-385.

13. Kraemer K, Zimmermann M. (2007) Nutritional anemia: Sight and Life Press Basel.

14. Schellenberg D, Schellenberg JR, Mushi A: The silent burden of Anaemia in Tanzania children, a community-based study. World Health Organ 2003, 81:581-590.

15. Awash S, pande V.K. (1998). Cause specific mortality in under-fives in urban slums of Lucknow, North India.J Trop paediatrics 44:358-361

16. Job C, Calis M, Phiri S. (2008). Severe Anaemia in Malawian children Eng. J Med 2008;358.888-899.

17. Newton RC, Warn PA, Winstanley AP, Marsh K. (1997). Severe Anaemia in children living in a malaria endemic area of Kenya. Trop med int health 1997;2 165-78.

18. Ashiwini K, Mandar K, Rajnish J, Kalantri S, Ulhar J (2010). Accuracy and reliability of pallor for detecting Anaemia: A Hospital based diagnostic accuracy study. PLOS one 5(1): e8545.

19. Stoltzfus R, Michele LD, Marco A, Keith PW, Hababuu MC, Lorenzo S, James T (1990) Clinical pallor is useful to detect severe Anaemia in populations where Anaemia is prevalent and severe Nutr 129(9):1675-81.

20. Zucker JR, Lackritz EM, Ruebush TK, Hightower AW, Adungesi JE, Were JB, Metchock KB, Patrick E, Campbell CC (1996). Childhood mortality during and after hospitalization in western Kenya: effects of malaria treatment regimen. Am J. Trop.Med hyg 55:655-660. 
21. Daly Z. (2015). Prevalence of iron deficiency and correlate of mild, moderateanaemic infants 6 to 11 months; mbala, Northern Province. Zambia electronic thesis or dissertation, university of British Colombia.

22. Uma D, Bhabani SD, Mohan CR, Pramod KR (2003). Effect of iron supplement on mild to moderate anaemia. Britishjou of Nutr 90,541550

23. Chatterjee A, Bosch RJ, Kupka R, Hunter DJ. Predictors and consequences of Anaemia among antiretroviral naïve HIV-infected and HIV-uninfected children in Tanzania.publi health nutrition 2010, 13:289-296.

24. Makubi AN, Mugushi F, Magesa PM, Roberts D. (2012) Risk factors for Anaemia among HIV infected children attending care and treatment clinic at muhimbili National Hospital in dar es salaam, Tanzania. Health2012,14:1-9

25. Ngesa O Mwambi (2014). Prevalence and risk factors of Anaemia among children aged 6 months and 14 years in Kenya. Plos one9(11): ell3726.cloi: 10.1371/journal.pon.0113756

26. Luo C, Mwela CM, Campbell J (1999). National baseline survey on prevalence and Aetiology of Anaemia in Zambia. Random cluster survey involving children, women and men

27. Vilamor E, Mbise R, Spieglman D, Ndossi Vitamin A Supplementation and other predictor of Anaemia among children from Dar es salaam, Tanzania. The American journal of tropical medicine and hygiene 2000,62:590-597

28. Crawley J (2004). Reducing the burden of Anaemia in infants and young children in malaria endemic countries of Africa: from evidence to action. Am J Trop Med Hyg 2004:71-:25-34

29. UN/ACC/SCN.4th Report on world nutrition situation ACC/SCN, Geneva,2000.

30. Angus BJ, White NJ. (1997). Vivo removal of malaria parasite from red blood cells without their destruction in acute falciparum malaria blood: 90: 2037-40

31. Phillis RE, Parvol G (1992). Anaemia of plasmodium falciparum malaria. Bailliers clini Haematol 1992; 5,315-30

32. Hilgar M (2012) Hematological manifestation in HIV infected children paediatric 191,119:547-549.
33. Tovo AP, De martino M, Gabiano C, Cappello N, Loy A, D'Elia R, Plebani A, Zuccotti GV, Dallacasa P, Ferraris G. (1992) Prognostic factors and survival in children with perinatal HIV infection: lancet 1992:1249-1253

34. Coyle TE (1997) Hematologic complications of human immunodeficiency virus infection and the acquired immunodeficiency syndrome. Med clin AM.81:449-470

35. Matt TT.et al. (2003) Micronutrient status of primary school girls in rural and urban areas of south Vietnam, asia.pac J clin nutr 12:178185.

36. Sinha N. (2008) Epidemiology correlates of nutritional Anaemia among children,6-35 months, in rural wardha, central India. Indian Jmed sc62:45-54

37. Mouneke V, Ibekur R etal. (2012) Factors associated with mortality in the under five children with Anaemia in Ebonyi, Nigeria. Indian paediatric 49:119-123

38. Villamer, E (2007) Vitamin A supplement and other predictors of Anaemia among children. Dar-es-salaam. American journal of tropical medicine and hygiene 2007,62:590597.

39. Magalhaels RJ, (2011) Mapping the risk of Anaemia in preschool age children: the contribution of malaria, helminth infection in west Africa.p20 med 2100<8: e1000 438

40. Owusu-Agyei S, Chandramohan D, Fryauff DJ, Koram KA, Binka FN, Nkrumah FK, Hoffman SL, Utz GC (2002) Characteristics of severe Anaemia and its association with malaria in young children of kassena nankana district of northern Ghana.AMJ trop med hyg 67:371-377

41. Brabin B, Premji Z, Verhoeff (2001) An analysis of anaemia and child mortality. The JNutri 131:6365-6485.

42. Akhwale WS, Obonyo C, Lum JK, Kaneko A, Eto H, Bjorkman A, kobayakawa T (2004) Anaemia and malaria at different altitudes in west highlands of Kenya acta trop 91:167175.

43. Magalhaes R, Clements A (2011) Mapping the risk of anaemia in preschool age children, the contribution of malnutrition, malaria and helminth infections in west Africa plos med 8: el000438. 
44. Bukele G, Wondimagegn A, Yaregal A, Lealem G (2014) Anaemia and associated factors among school age children, southern ethopia.BMC Haematology 14:13

45. Mohammad SE, Awad EE, Ahmed AM, Abbas A (2014) prevalence of anaemia among schools(khalawi) in central Sudan, a cross sectional study. Pan afrc.med journal

46. Ughasoro MI, Emodi I, Ibe BC (2011) prevalence of moderate and severe anaemia in Children under five at university of Nigeria Teaching Hospital, Enugu, south east Nigeria. Paediatric research, PR 2011714

47. Simbauranga RH, Kamugisha E, Hokororo A, Kidenya BR, Makani J (2015) prevalence and factors associated with severe anaemia among under five children hospitalized at Bugando Medical Center, Mwanza, Tanzania. BMC Haematology 2015 15:13

48. Kuziga F, Yeka A (2017) prevalence and factors associated with Anaemia among children aged 6 to 59 months in Namuluna District, Uganda. A cross sectional study. BMC paediatrics ISSN:1471-2431.
49. Brian SE, Alan AS, Gregory DH (2002) A prospective cross-sectional study of Anaemia and peripheral iron status in HIV infected children in cape town, south Africa. BMC infectious disease 2002:2-3.

50. Rosemary F, Eliane SC, Ana Paula CP (2010) Prevalence of Anaemia in under 5 children in a children's Hospital in Recife, Brazil. Rev Bras Hematol Hemoter 2011:33(2):100-104

51. Quinto L, Aponte JJ, Menedez C, Navia MM, Thompson R, Alonso PL (2006) Relationship between Hemoglobin and Hematocrit in the definition of anaemia. Trop Med inter Health 2006 aug;11(8) 1295-302.

52. Qasem A, Friel J (2015) An Overview of Iron in term breastfed infants. Clinical medicine insights Paediatrics 2015:9 79-84.

53. Osazuwa F (2011) A significant association between intestinal infection and Anaemia burden in children in rural communities of Edo state, Nigerian Am J Med sci.2011;3(1):30-34

54. Samson A, Ogbenna A (2016) Morphologic evaluation of Anaemia. I. Biomed (Aligarh)8:322; doi $\quad 10.4172 / 0974$ $8369,1000322$. 